\title{
BMJ Open The importance of maternal diet quality during pregnancy on cognitive and behavioural outcomes in children: a systematic review and meta-analysis
}

\author{
Tiril Cecilie Borge,${ }^{1}$ Heidi Aase,${ }^{2}$ Anne Lise Brantsæter, ${ }^{3}$ Guido Biele ${ }^{1}$
}

To cite: Borge TC, Aase H, Brantsæter AL, et al. The importance of maternal diet quality during pregnancy on cognitive and behavioural outcomes in children: a systematic review and meta-analysis. BMJ Open 2017;7:e016777. doi:10.1136/ bmjopen-2017-016777

- Prepublication history and additional material for this paper are available online. To view these files please visit the journal online (http://dx.doi. org/10.1136/bmjopen-2017016777).

Received 9 March 2017 Revised 24 May 2017 Accepted 22 June 2017

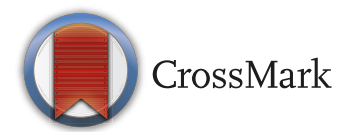

${ }^{1}$ Department of Child Health, Norwegian Institute of Public Health, Oslo, Norway

2Department of Child Development, Norwegian Institute of Public Health, Oslo, Norway

${ }^{3}$ Department of Environmental Exposure and Epidemiology, Norwegian Institute of Public Health, Oslo, Norway

Correspondence to Tiril Cecilie Borge; tibo@fhi.no

\section{ABSTRACT}

Objectives This systematic review and meta-analysis provides a quantitative summary of the literature exploring the relationship between maternal diet quality during pregnancy and child cognitive and affective outcomes. We investigate whether there are indications for robust associations and aim to identify methodological strengths and challenges of the current research to provide suggestions of improvement for future research.

Design and participants Relevant studies were identified through a systematic literature search in relevant databases. All studies investigating maternal diet quality during pregnancy in relation to child cognitive or affective functioning in children of elementary school age or younger were assessed for inclusion.

Results 18 relevant studies, comprising 63861 participants were identified. The results indicated a small positive association between better maternal diet quality during pregnancy and child functioning. We observed publication bias and significant heterogeneity between studies, where type of diet classification, publication year and outcome domain together accounted for about 30\% of this heterogeneity. Trim and fill analysis substantiated the presence of publication bias for studies in the affective domain and showed an adjusted effect size of Hedge's $g=0.088(p=0.0018)$ (unadjusted $g=0.093(p=0.03))$. We observed no publication bias in the cognitive domain, where results indicated a slightly larger effect size $(g=0.14$ $(p<0.0001))$ compared with that of the affective domain. The overall summary effect size was $g=0.075(p<0.0001)$ adjusted for publication bias (unadjusted $\mathrm{g}=0.112$ $(p=0.0001))$. Child diet was not systematically controlled for in the majority of the studies.

Conclusion The results indicated that a better maternal diet quality during pregnancy has a small positive association with child neurodevelopment, with more reliable results seen for cognitive development. These results warrant further research on the association between maternal diet quality during pregnancy and cognitive and affective aspects of child neurodevelopment, whereby it is crucial that future studies account for child diet in the analysis.

\section{INTRODUCTION}

The importance of adequate nutrition during foetal life for long-term physical health is well

\section{Strengths and limitations of this study}

- This is the first article to summarise research into the association between maternal diet quality during pregnancy and child neurodevelopment.

- Major strengths of this research are the use of metaanalytic methods for calculation of average effect sizes and investigation of publication bias.

- This study highlights strengths and challenges of an emerging research field, thus building the foundation for improved future research.

- A limitation is the relatively small number of relevant studies identified for inclusion in the meta-analysis.

- Since this meta-analysis is based on observational studies, no strong causal interpretations about the association of maternal diet quality during pregnancy and child neurodevelopment can be made.

documented. ${ }^{1}{ }^{2}$ However, the relationship between maternal nutrition during pregnancy and child mental health is less established. ${ }^{3}$ The prenatal environment is crucial in relation to cognitive development of the child, particularly during critical periods of brain development, which highlights the fetus' need for optimal nutrition. ${ }^{4}$ There are documented detrimental effects of severe maternal malnutrition during pregnancy, ${ }^{5}$ and severe deficiencies of certain micronutrients, like iron and iodine ${ }^{6}$ on child neurodevelopment and general cognitive functions, as well as severe deficiencies of folate and choline on child neural tube defects, ${ }^{7}$ but the impact of more subtle variations in maternal diet quality ${ }^{\mathrm{i}}$ on child neurodevelopment has received little attention until recently.

It has become increasingly recognised that investigating the impact of diet on most

'When using the term 'maternal diet quality' in this paper, we are always referring to the maternal diet quality during pregnancy, unless otherwise stated. 
disease outcomes cannot be done solely by investigating single nutritional components separately. Considering that the human diet consists of thousands of biologically active components, with only a fraction having been defined as nutrients, it is likely that the majority of the dietary constituents affect human health in an interdependent manner. Looking at overall diet quality, for example, through dietary patterns, is believed to represent a valid and meaningful measure of overall nutrient intake ${ }^{8}$ and is a promising approach when aiming to study diet related associations. ${ }^{9}$

To date, no meta-analysis has summarised research on maternal diet quality and child neurodevelopment. As the research interest for this topic is rapidly increasing, it is valuable to summarise the research to date on this topic using statistical procedures. The aim of this meta-analysis is to provide a quantitative summary of the existing literature exploring the relationship between maternal diet quality and child cognitive and affective outcomes. The goals are to investigate whether there are indications for robust associations, despite the limited amount of studies available and to identify methodological strengths and challenges of the current research to provide suggestions of improvement for future research.

\section{METHODS}

As a scientific guideline for this manuscript, we followed the PRISMA statement. ${ }^{10}$

\section{Defining exposure and outcome measures}

Despite the increased interest in studying dietary patterns as a measure for diet quality, the current literature regarding the associations between maternal dietary patterns during pregnancy and child neurodevelopmental outcomes is sparse. A preliminary literature search resulted in only four articles with defined maternal dietary patterns as exposure relevant for inclusion into the meta-analysis. Consequently, in order to increase the basis for analysis, articles with dietary exposures believed to be good proxies for maternal diet quality were included. Based on the existing literature, fish intake, ${ }^{11} \Omega-6 / \Omega-3$ fatty acid ratio, ${ }^{12}$ saturated fat intake ${ }^{13}$ and dietary fibre (reflecting intake of whole-grain foods, vegetables, fruits, legumes and nuts) ${ }^{14}$ were considered good proxies for maternal diet quality. In previous research, based on dietary data from large cohorts where dietary patterns have been identified with data driven methods, consumption of fish and fibre-rich foods, as well as limited intake of saturated fats, have consistently been associated with a healthier dietary pattern, both in the general population ${ }^{15}$ and in pregnant women. ${ }^{816}$ Additionally, fibre-rich foods, fat quality and fish are incorporated into established healthy food indices, like the Mediterranean diet index ${ }^{17}$ and the Healthy Eating Index (HEI-2010). ${ }^{18}$ Considering the already limited amount of available relevant literature, few limitations were put on the possible outcome as long as it covered a child neurodevelopmental domain, like cognition (IQ and language) or effect (externalising and internalising difficulties).

\section{Search criteria and strategies}

An extensive search string was developed as to not exclude any relevant literature and adapted to each database, including key words relating to maternal diet quality, child mental health, cognitive function (language, communication skills, IQ) neurodevelopmental disorders (ADHD, ODD, CD, ASD) and affective functioning. The following exclusion criteria were applied: children with very low birth weight, children older than elementary school age and studies focusing on single micronutrients and/or supplements. The search string was developed by TCB in collaboration with a specialist librarian. For full search string, see online supplementary table 1 .

\section{Data collection and extraction process}

After identification of original articles through the initial search, excluding duplicates, TCB and ALB independently screened title and/or abstract of each study. TCB's and ALB's final list of eligible and possibly eligible studies were then crosschecked and read in full text by both. If both reviewers were unsure whether an article was eligible for inclusion, GB was consulted to assure coherence regarding the final selection of articles for inclusion. After identification of the eligible articles the relevant information from each study was extracted by TCB (eg, year of publication, total number of participants, dietary exposure and outcome measures assessed, confounders controlled for and reported effect sizes) in collaboration with GB and ALB. TCB and GB then assessed individual study quality with the Newcastle-Ottawa Scale (NOS) for assessing the quality of cohort studies in meta-analysis. ${ }^{19}$

\section{Individual study quality assessment}

For each eligible study included in the meta-analysis, we performed an individual study quality assessment using the NOS. ${ }^{19}$ The NOS provides an easy to use study quality checklist and is recognised by Cochrane. ${ }^{20}$ The scoring system is based on the assessment of three aspects of a study: Selection (representativeness of cohort and exposure assessment); Comparability (ascertainment of confounding) and Outcome (assessment of outcome and follow-up). The scoring system categorises studies as being of good, fair or poor methodological quality, whereby insufficiency in one of the domains results in a 'poor' rating. While the NOS has been criticised for an overly general definition of quality criteria, ${ }^{21}$ this generality allows for a wide application of the scale. Moreover, the intent of the scale is clear: A good rating of the Selection dimensions requires a representative sample and high quality measurement; a good rating of the Comparability dimension requires control of appropriate confounders and a good rating of the Outcome dimensions requires a high quality measurement of outcomes and/or high follow-up rates or correction for non-random dropout. 


\section{Analysis of reported effect sizes}

To be able to compare the results of the studies, association measures reported in each individual study had to be transformed into a standardised effect size. ${ }^{\text {ii }}$ The effect size measure used for this meta-analysis was Hedges' g, which is a more conservative effect size measure compared with Cohen's d. ${ }^{22}$ Effect sizes were calculated to reflect the association between better maternal diet quality and the different cognitive and affective outcomes, where a positive value indicates a better outcome, hence better language development or general cognitive functioning, or less affective problems.

The meta-analysis was conducted with the $\mathrm{R}$ statistical software version 3.2.2, using the Metafor package, version $1.9-8 .^{23} 24$ Because the included studies were heterogeneous with regard to neurodevelopmental outcomes, choice of statistical procedures and effect sizes, we used a random-effects model (REM) for analyses. ${ }^{22}$ This approach models variance between the included studies and assumes that observed differences in effect sizes are due to both sampling error and true effect size differences in the studies' background populations. ${ }^{22}$

A restricted maximum-likelihood method for estimation of heterogeneity was used to compute relevant Q-statistics, with corresponding $\mathrm{I}^{2}$-statistics. The $\mathrm{Q}$-statistics indicate whether there is statistically significant heterogeneity across the studies' effect sizes, whereas the $\mathrm{I}^{2}$-statistics indicate the extent of heterogeneity. A significant Q-statistic indicates systematic (as opposed to random) variation of effect sizes between studies.

\section{Possible moderators}

If the REM analyses indicate presence of heterogeneity, moderator analyses can be used to investigate potential causes of this heterogeneity. We used meta-regressions where we added potential moderator variables individually to separate regression models in order to assess their effect on the association between exposure and outcome. The following factors were available for consideration as possible moderators: Publication year, child age at assessment, outcome domain (cognitive, affective), diet category (type of diet classification-whether the exposure is defined as maternal dietary pattern or a proxy for maternal dietary pattern) and instrument category (measurement of outcome-questionnaire or neuropsychological test), as they are all factors which might moderate the association between exposure and outcome. The categorical factors were dichotomous.

\section{Publication bias}

Publication bias describes a situation in which the decision to publish research results depends on obtaining statistically significant results. ${ }^{25}$ Indeed, studies reporting statistically significant results are more likely to be published

\footnotetext{
${ }^{\text {ii }}$ When referring to 'effect size' in this paper we are not indicating causality-it is merely the statistical term of the reported outcome measures.
}

than studies reporting results that are not statistically significant. ${ }^{26}$ One visual meta-analytic tool traditionally used to investigate publication bias is the funnel plot. ${ }^{27}$ To complement the potential subjectivity of visual inspection of funnel plots the Egger's regression test for funnel plot asymmetry ${ }^{28}$ can be performed.

In the presence of publication bias, a 'trim and fill' approach can be used to correct for it. The trim and fill method uses effect sizes and their SE to generate a 'complete' distribution of effect sizes that likely would have been reported without publication bias by adding imputed studies to the reported studies. If the average effect sizes calculated from published and 'complete' effect sizes do not differ noticeably, one can have more confidence in the average effect size from a group of studies that appear afflicted by publication bias. ${ }^{25}$ As there is some discussion in the literature regarding the optimal methods for adjustment for publication bias, ${ }^{29}$ a meta-regression to adjust for publication bias using the SE of effect sizes as a moderator should also be performed.

\section{RESULTS}

\section{Study sample and selection}

Ovid (Embase, Psychinfo, Medline), PubMed and ISI: WEB of science were searched on 16 November 2016 using the full search string. Additionally, we explicitly searched for relevant studies that employed a priori dietary quality indices (like the HEI-2010 and Mediterranean diet index).

A total of 18 studies fit the inclusion criteria, ${ }^{30-47}$ the majority reporting several outcome measures. The study selection process is visualised in figure 1 .

All included studies were observational in nature and based on a prospective cohort design or case-control design, with baseline measures of maternal dietary intake during pregnancy and subsequent measurement of child cognitive or affective functioning, at one or more time points.

All studies collected information on maternal dietary intake with the use of a food frequency questionnaire (FFQ), either self-administered or by a trained interviewer, with some using validated FFQs; and/or a fooddiary. Data obtained with these instruments were used as the basis for the definition of dietary patterns, estimation of fish/seafood intake, fruit intake, saturated fat intake and estimation of $\Omega-6 / \Omega-3$ fatty acid ratio based on intake.

Four studies used maternal dietary patterns as exposure variables, ${ }^{30} 353940$ either defined by the use of principal component analysis or confirmatory factor analysis. In three studies, ${ }^{3035} 40$ two distinct dietary patterns were identified: one 'healthy' and one 'unhealthy', while only an unhealthy dietary pattern was defined in the fourth. ${ }^{39}$ The healthy dietary patterns were generally characterised by higher intakes of vegetables, fish, legumes, wholegrains and vegetable oils, while the unhealthy dietary patterns consisted of higher intakes of processed foods (fried 


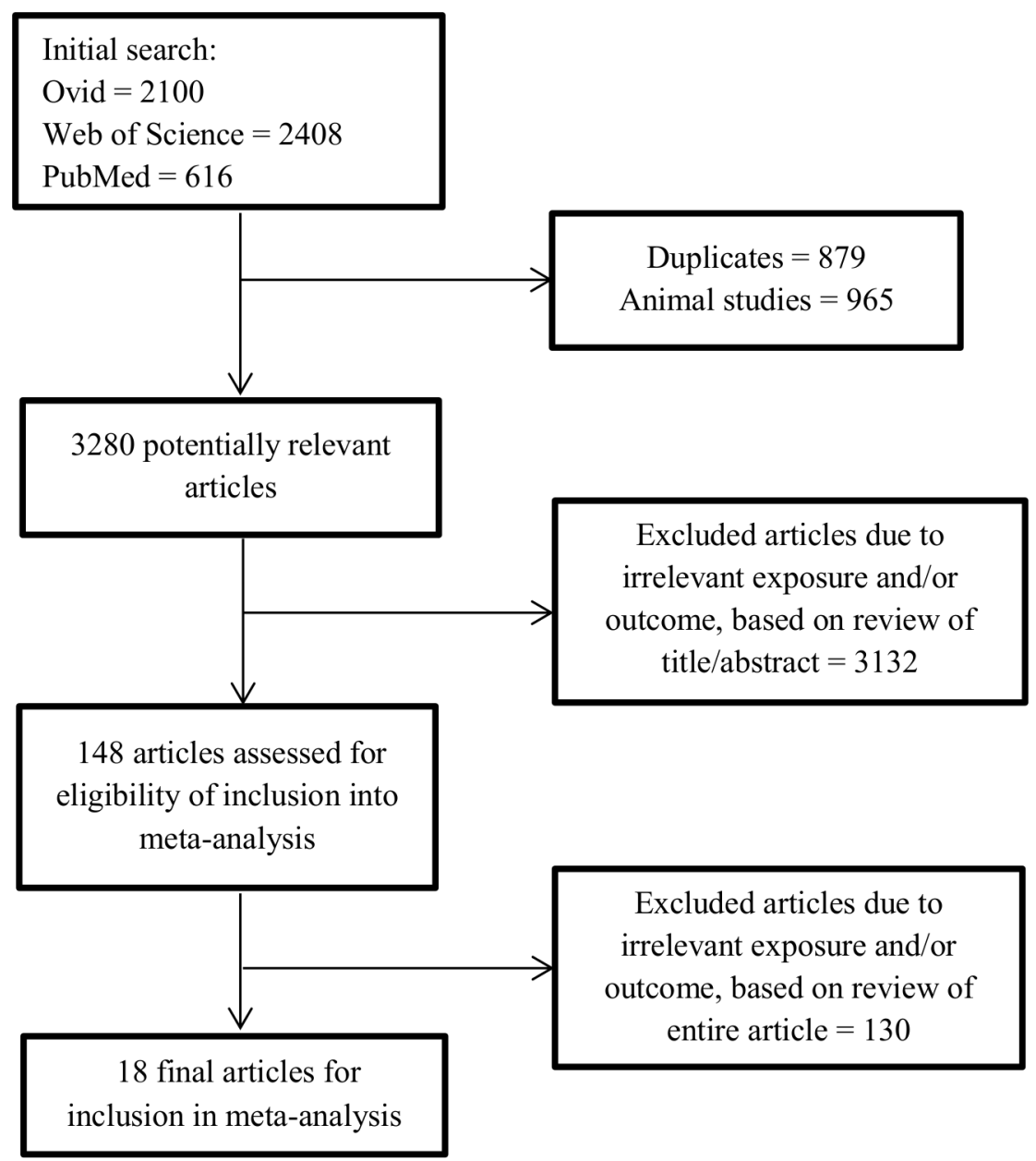

Figure 1 Flow diagram of the study selection process.

foods, French fries, meats) confectionary foods (cakes, candy, sugary drinks), refined cereals and salty snacks.

Eleven studies used maternal fish intake as exposure, ${ }^{31-34} 36-3841424647$ where the studies categorised fish intake into groups based on meals/portions or grams eaten per day or week. The remaining three studies used $\Omega-6 / \Omega-3$ fatty acid ratio, ${ }^{43}$ saturated fat intake ${ }^{45}$ and fruit intake ${ }^{44}$ as their exposure variable. All studies were published in the period from 2004 to 2016, with study populations ranging from 48 to 23020 mother-child pairs (table 1).

\section{Outcome measures}

Table 2 summarises the wide range of different neuropsychological instruments that were used across the studies to assess cognitive and behavioural functions. A total of 18 original instruments were used in addition to one self-developed instrument, comprising both questionnaires and neuropsychological tests.

\section{Confounders}

Overall, the studies controlled for a number of different factors are depicted in online supplementary table 2. Studies varied greatly in which confounders they included in the analysis, with SES being the only confounder considered by all studies.
Individual study quality assessment

Each study was evaluated with the NOS checklist; please see online supplementary table 3 for individual study scoring information. Of the 18 included studies, nine were rated as of 'fair' quality and nine as of 'poor' quality. No study received the rating 'good' because none of the studies that used high-quality measurements also adequately dealt with self-selection into studies and selective dropout of participants. All 'poor' ratings were due to insufficiencies in the 'Outcome' dimension of the NOS in studies that measured outcomes through self-reports (independent blind assessments or record linkage is preferred by the NOS) and that additionally did not account for selective dropout between exposure and outcome assessments.

\section{Computation of effect sizes}

None of the included studies reported Hedges' $g$ as their effect size. The compute.es package ${ }^{48}$ was used to calculate Hedges' $\mathrm{g}$ for the studies reporting the following: (1) For OR, Hedges' $\mathrm{g}$ was calculated using the 'lores' function (based on log of OR and its corresponding variance), (2) for $p$ values (with information of group sample sizes), Hedges' $\mathrm{g}$ was calculated using the 'pes' function and (3) for correlation coefficient (r), Hedges' $g$ was calculated using the 'res' function. 

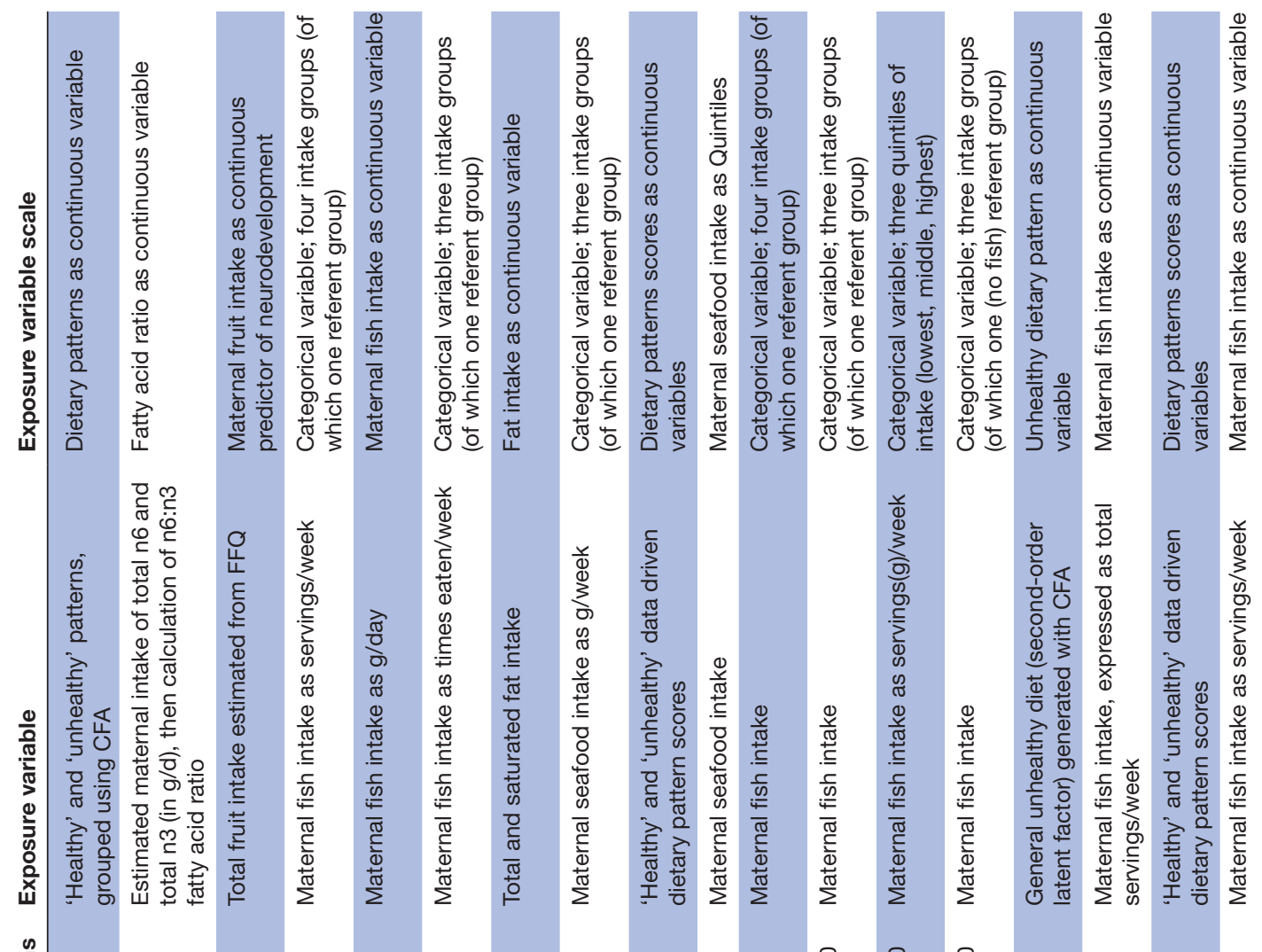

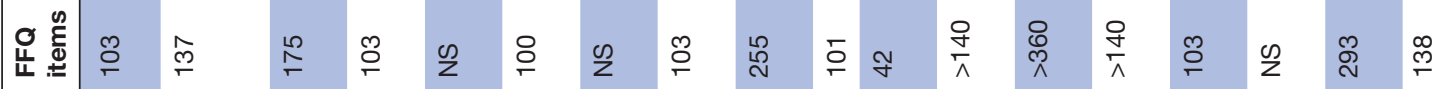

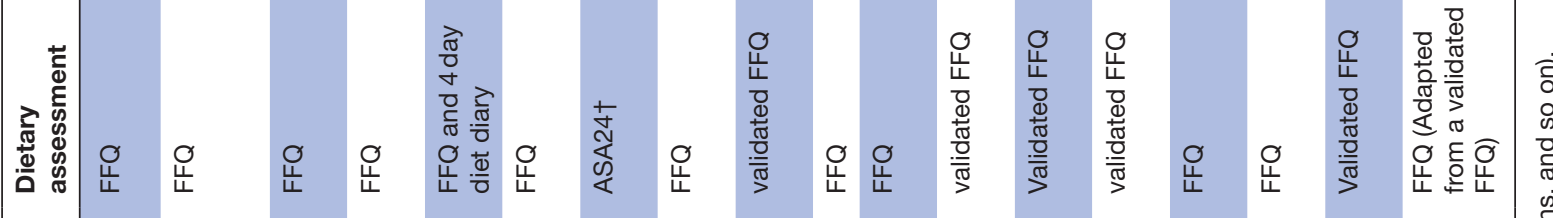

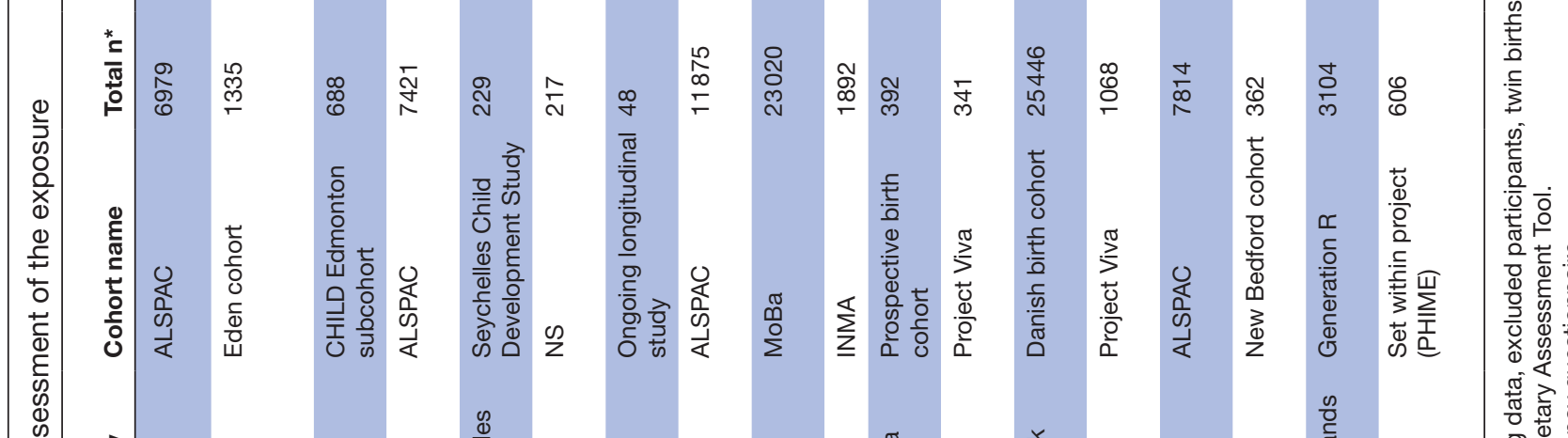

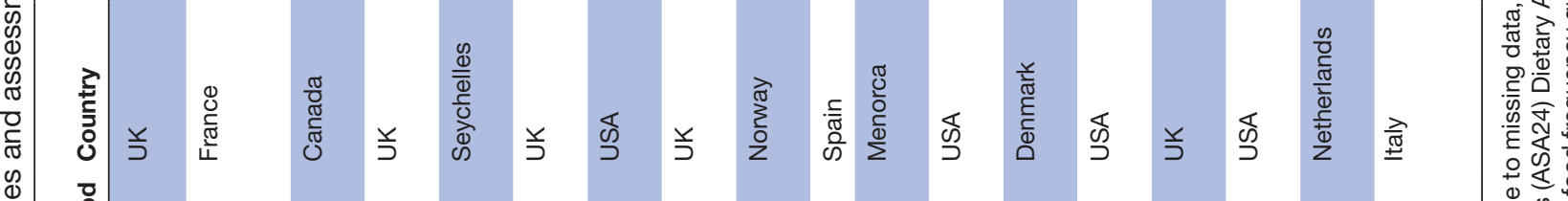

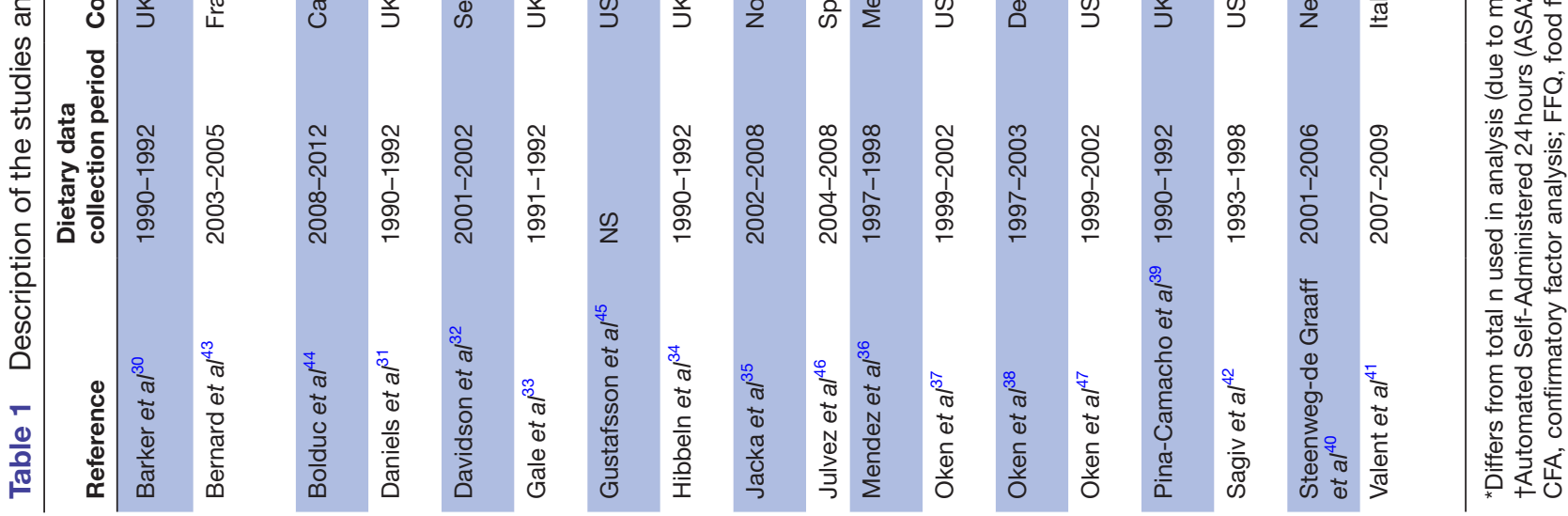


Table 2 Overview of outcomes assessment methods

\begin{tabular}{|c|c|c|c|}
\hline Reference & Cognitive outcome assessment ${ }^{\star}, \dagger$ & $\begin{array}{l}\text { Affective outcome } \\
\text { assessment }^{*}, \dagger\end{array}$ & $\begin{array}{l}\text { Child age at } \\
\text { assessment }\end{array}$ \\
\hline Barker et $\mathrm{a}^{30}$ & WISC-III ${ }^{\mathrm{n}}$ & & 8 years \\
\hline Bernard et $a l^{43}$ & $\mathrm{MCDI}^{\mathrm{q}}, \mathrm{ASQ}^{\mathrm{q}}$ & & 2 and 3 years \\
\hline Bolduc et $\mathrm{al}{ }^{44}$ & BSID-III (cognitive subscale) ${ }^{n}$ & & 1 year \\
\hline Daniels et $\left.a\right|^{31}$ & $\mathrm{MCDI}^{\mathrm{q}}$ & & 1.25 and 1.5 years \\
\hline Davidson et $a^{32}$ & $\begin{array}{l}\text { BSID-II (Psychomotor Developmental } \\
\text { Index) }\end{array}$ & & 2.5 years \\
\hline Gale et $a l^{33}$ & WASI $^{\mathrm{n}}$ & $\mathrm{SDQ}^{\mathrm{q}}$ & 9 years \\
\hline Gustafsson et a $\left.\right|^{45}$ & & $I B Q-R^{q}$ & 4 months \\
\hline Hibbeln et $\left.a\right|^{34}$ & WISC-III ${ }^{\mathrm{n}}$ & $\mathrm{SDQ}^{\mathrm{q}}$ & 7 years \\
\hline Jacka et $\left.a\right|^{35}$ & & $\mathrm{CBCL}^{\mathrm{q}}$ & 1.5 years \\
\hline Julvez et $a l^{46}$ & $\begin{array}{l}\text { BSID (mental and psychomotor } \\
\text { developmental index) }{ }^{n}, \text { MCSA }^{n}\end{array}$ & & $\begin{array}{l}14 \text { months and } \\
5 \text { years }\end{array}$ \\
\hline Mendez et $\left.a\right|^{36}$ & $\operatorname{MCSA}^{n}$ & & 4 years \\
\hline Oken et $\left.a\right|^{37}$ & PPVT $^{\mathrm{n}}$, WRAVMA $^{\mathrm{n}}$ & & 3years \\
\hline Oken et $\mathrm{a}^{38}$ & $\begin{array}{l}\text { Self-developed instrument ( } 9 \text { q's regarding } \\
\text { developmental milestones) }{ }^{q}\end{array}$ & & 1.5 years \\
\hline Oken et al ${ }^{47}$ & WRAML $^{\mathrm{n}}, \mathrm{KBIT}-\mathrm{II}^{\mathrm{n}}$ & & 7.7 years $\ddagger$ \\
\hline Pina-Camacho et $a^{39}$ & & $\mathrm{CITS}^{q}$ & 2 years \\
\hline Sagiv et al/2 & WISC-III ${ }^{n}$ & CRS-T ${ }^{q}$ & 8 years \\
\hline Steenweg-de Graaff et al ${ }^{40}$ & & $\mathrm{CBCL}^{\mathrm{n}}$ & 3.5 years \\
\hline Valent et $a l^{41}$ & & $\begin{array}{l}\text { BSID-III (socioemotional } \\
\text { subscale) }^{n}\end{array}$ & 1.5 years \\
\hline
\end{tabular}

${ }^{*}$ Outcomes are administered either as a questionnaire (q) or neuropsychological test (n).

†Full name of instruments in alphabetical order: ASQ, Ages and stages questionnaire; BSID, Bayley Scales of Infant Development; CAST, Childhood Asperger Syndrome Test; CBCL, Child behaviour checklist; CITS, Carey infant temperament scale; CRS-T, Conners rating scaleteacher; DDST: Denver Developmental Screening Test; IBQ-R, Revised infant behaviour questionnaire; KBIT-II, Kaufman Brief Intelligence Test second edition; MCDI, MacArthur Communicative Development Inventory; MCSA, McCarthy Scales of Children's Abilities; PDI, Psychomotor Developmental Index; PPVT, Peabody Picture Vocabulary Test; SDQ, Strength and Difficulties Questionnaire; WASI, Wechsler Abbreviated Scale of Intelligence; WISC, Wechsler Intelligence Scale for Children; WRAML, Wide Range Assessment of Memory and Learning; WRAVMA, Wide Range Assessment of Visual Motor Abilities.

$\ddagger$ Median age in years of children at outcome assessment.

Some studies did not report all the required information to calculate Hedges' $\mathrm{g}$ in the compute.es package. For the studies reporting OR, where group sample sizes were not reported, the method for converting OR to Cohens' d proposed by Chinn ${ }^{49}$ was used. For mean difference in standardised test score, Hedges' $\mathrm{g}$ was calculated using $\mathrm{SD}$ and mean difference. For regression coefficient $(\beta)$, Hedges' g was calculated using p-value, SE and z-statistics. For Cohens' d, Hedges' $g$ was calculated using the formula proposed by Lakens. ${ }^{50}$ For studies lacking $\mathrm{p}$ value, CIs, SDs or SEs, the required inferential statistics were calculated in advance of the final effect size estimation by using appropriate formulas. $^{51-53}$

\section{Summarising effect sizes}

After Hedges' g had been calculated, the effect sizes were further summarised as many studies reported several effect sizes for the same exposure-outcome combination. Preferably, only one effect size per study should be retained; ${ }^{22}$ however, this was considered inapplicable, due to the large variations in neurodevelopmental outcomes assessed in the different studies. After careful consideration, four outcome dimensions (externalising, internalising, socioemotional, cognitive) covering the affective and general cognitive domains were chosen. Selection of the outcome measures into each respective domain was based on (1) a thorough review of the properties of each instrument with regard to what area of development the instrument is aimed at measuring based on the manual for each instrument and (2) research indicating that language, cognition and executive functions are more strongly correlated with each other than with affective functioning. ${ }^{545}$

Additionally, we applied the following rules to reduce the number of effect sizes per study, aiming to obtain only one effect size per outcome dimension per study:

1. For fish/seafood intake, if more than two intake groups had been defined, we only included the group which best corresponded to what is considered a 
healthy diet by the national health authorities, which is 2-3 servings per week for total fish intake, where about half should be fatty fish. ${ }^{11}$

2. If studies reported statistics for a total score as well as subscales of an outcome measure, only the effect size for the total score was included in the analyses.

3 . If the effect sizes were based on sample stratification (eg, by breastfeeding duration), measures were collapsed. Collapsed effect sizes were calculated as weighted means of Hedges' g over comparisons, whereby weights depended on the $\mathrm{n}$ of each comparison.

4. If OR was calculated for both high and low test score in the original article, only the effect sizes corresponding to the high test score was retained.

5. If effect sizes were reported for all types of fish as well as oily fish, only all types of fish were included in the final analysis, as to make the exposure definition as homogenous as possible.

6. If studies reported associations with both an unhealthy and a healthy dietary pattern, the effect size for the unhealthy dietary pattern was reversed and then averaged with the healthy dietary pattern.

7. For studies reporting several eligible effect sizes for an outcome dimension, the effect size based on the most valid measurement instrument was used (eg, effect size from a neuropsychological test vs questionnaire or a validated questionnaire vs a not validated questionnaire).

8. For studies that report more than one effect size relevant for inclusion in one domain based on the same type of instrument, the average weighted effect size across those reported were included after Hedges $g$ had been calculated.

9. For reported effect sizes where corresponding outcome dimensions were unclear (eg, based on inadequate reporting of instrument properties) and not resolved with discussion among the reviewers, these effect sizes were excluded. This occurred for three separate instruments, each from different studies. ${ }^{43446}$

Application of these rules resulted in a total of 26 separate effect sizes. Only the fully adjusted effect sizes from each study were chosen. We initially considered including the corresponding unadjusted effect sizes for each study, however only four studies provided this information, ${ }^{33} 354142$ and the studies that reported minimally adjusted results adjusted for different variables.

The 18 studies included in the final meta-analysis comprised a total of $63861^{\mathrm{iii}}$ participants and 26 separate effect sizes divided into four different cognitive or affective dimensions. These effect sizes with corresponding CIs are depicted in the forest plot in figure 2. ${ }^{\text {iv }}$ The

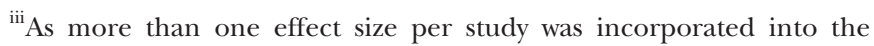
meta-analysis, with sometimes differing $\mathrm{n}$ between neurocognitive domains, the largest $\mathrm{n}$ for each study was used as a basis for total $\mathrm{n}$.

${ }^{\text {iv }}$ The data in figures 2, 3 and 4 are based on adjusted SEs to account for
}

size of each square reflects the precision of the effect size estimate by means of the weight that is assigned to each respective study when the summary effect size is computed. A larger square equals larger weight assigned to that study.

\section{Effect size dependencies}

There are several sources of effect size dependencies within our sample of studies. First, some of the included studies use subpopulations of the same cohort sample, while using different outcome measures at different time points: Four of the studies ${ }^{30} 313439$ were based on subsamples of the ALSPAC cohort, and two studies ${ }^{37} 47$ were based on subsamples from the Project Viva cohort. Second, some of the studies included in this meta-analysis $^{33-35}{ }^{40}$ report multiple effect sizes.

We used a weighting scheme and calculated robust SEs to account for these sources of dependencies. ${ }^{56}$ Weights were adjusted for studies that contribute multiple effect sizes by recalculating them such that the sum of the weights of all effect sizes from a study reflect the sample size of that study. When using the Metafor package which calculates weights from effect size variances or SEs, this can be achieved by calculating effect size variances with adjusted $\mathrm{N}$. In particular, we adjusted $\mathrm{N}$ for study i such that: $\mathrm{aN}_{\mathrm{i}}=\frac{\mathrm{N}_{\mathrm{i}}}{\sum_{\mathrm{j}}^{\mathrm{k}} \mathrm{N}_{\mathrm{j}}}$ Here, $\mathrm{k}$ is the number of effect sizes from a study sample (eg, ALSPAC) and $\mathrm{N}_{\mathrm{j}}$ are the sample sizes for the different effect sizes. When estimating average effect sizes for specific domains, this approach corrects for multiple effect sizes for one domain coming from one study sample. When estimating the overall effect size this approach corrects for multiple contributions of effect sizes from one or more domains from one study sample. Hence, one study could be allocated different weights, depending on the meta-analytic model. Optimally, the calculation of overall effect sizes would also account for the covariance between effects in different domains; however, the reviewed articles did not provide this information. The employed weighting scheme implies an assumed correlation of $\rho=0.5$.

For the two REMs investigating for publication bias (trim and fill and with $\mathrm{SE}$ as moderator) the adjusted SEs based on the above formulae was used. For the original REM we used the reported effect sizes and corresponding adjusted variance as a basis for the calculations and obtained robust $\mathrm{SEs}^{56}$ using Metafor's 'robust' function. We chose this robust estimator function as it is appropriate to use for models with unspecified heteroscedasticity, ${ }^{23}$ which is the case with all studies reporting multiple effect sizes that are included in this meta-analysis.

studies contributing with multiple outcomes as described in the 'effect size dependencies' section. 


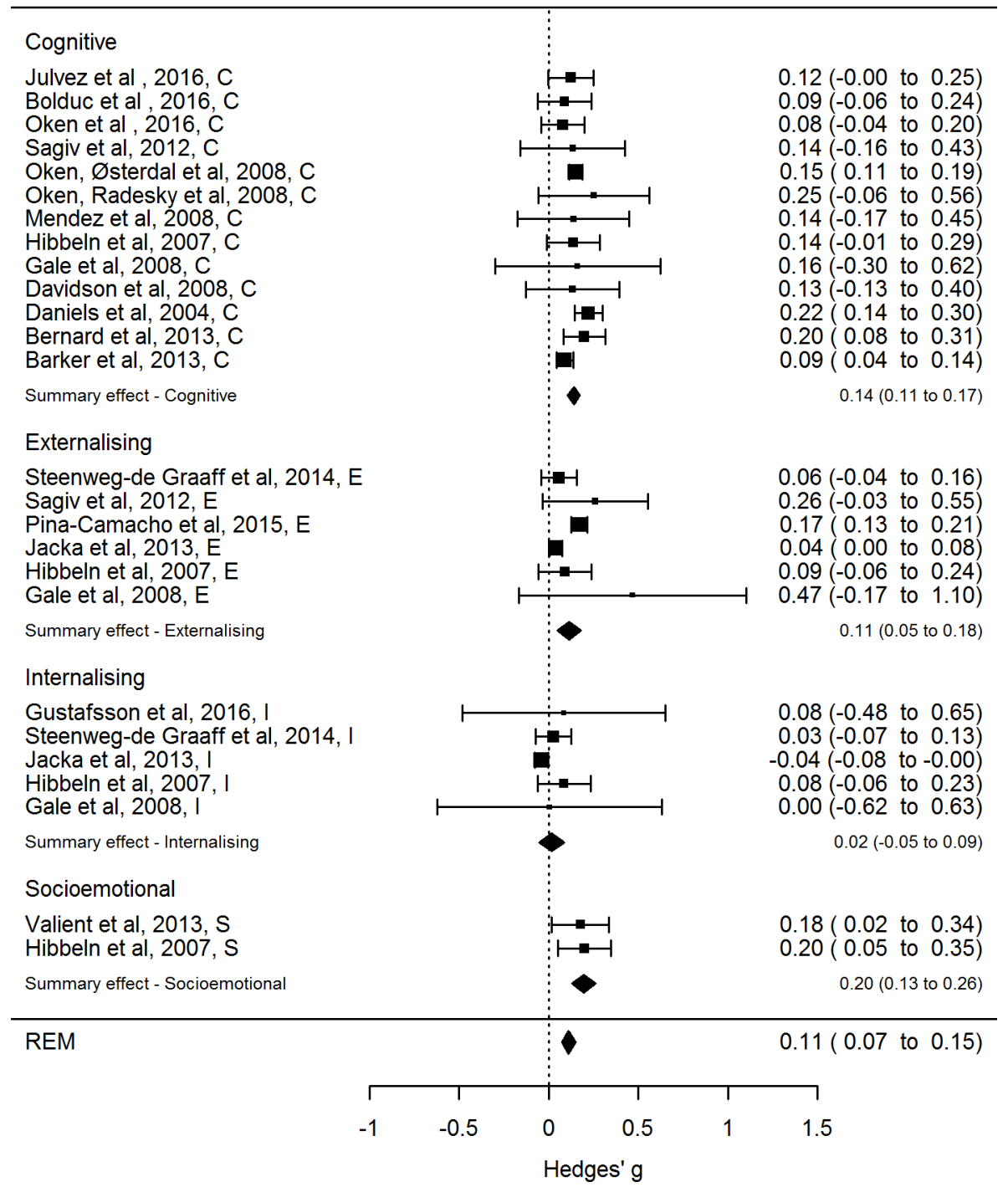

Figure 2 Forest plot of original REM of all included studies, with summary effect size for the cognitive and affective dimensions as well as the overall summary effect size.REM, random-effects model. REM, random-effects model.random-effects model

\section{Random-effects model}

Three separate REMs were fit: one across all studies to yield an overall summary effect size, one for the cognitive domain and one for the affective domain. Table 3 provides a summary of the three REMs, including test results for heterogeneity (Q-statistics and $\mathrm{I}^{2}$-statistics). For the original REM the effect sizes are typically larger for the cognitive domain $(\mathrm{g}=0.14)$, compared with the affective domain ( $g=0.093$ ), while the summary effect size across both domains is $\mathrm{g}=0.112$.

\section{Heterogeneity}

As can be seen from the $Q$ and $\mathrm{I}^{2}$ statistics in table 3, there is a significant degree of heterogeneity present for the overall summary effect size, indicating a systematic difference in effect sizes between the studies. As possible sources of this heterogeneity, we investigated publication bias and performed a moderator analysis on all included studies.

\section{Publication bias}

The Egger's regression test for funnel plot asymmetry was not significant $(\mathrm{p}=0.1581$ ), which might be mainly due to low power. To get a visualisation of possible publication bias, a funnel plot is depicted in figure 3 . $^{\text {iv }}$

If no publication bias was present, approximately $95 \%$ of the points for the original effect sizes should be located within the white funnel area ${ }^{25}$ and should be roughly distributed evenly to the left and to the right of the vertical line illustrating the overall summary effect size. Because this is not the case, a trim and fill analysis was performed and the results are displayed in figure $4 .^{\S}$

The imputed effect sizes (open circles) are all smaller than the summary effect size, and the trim and fill 
Table 3 REM statistics for separate meta-analyses for overall summary effect size, cognitive domain and affective domain, including test for heterogeneity

\begin{tabular}{|c|c|c|c|c|c|c|c|c|c|c|c|c|}
\hline \# & Outcome & Model type & $\mathbf{N}^{\mathbf{s}}$ & $\mathbf{N}^{p}$ & Hedges' g & SE & $z$ & p Value & df & $\mathbf{Q}$ & Qp & $I^{2}(\%)$ \\
\hline \multirow[t]{3}{*}{1} & \multirow{3}{*}{$\begin{array}{l}\text { Summary } \\
\text { Effect Size }\end{array}$} & Original REM & 26 & $63861^{*}$ & 0.112 & 0.023 & 4.9 & 0.0001 & 25 & 102 & $<0.0001$ & 69 \\
\hline & & $\begin{array}{l}\text { REM with SE as } \\
\text { moderator }\end{array}$ & & & 0.079 & 0.029 & 4 & 0.0065 & 24 & 93 & $<0.0001$ & 68 \\
\hline & & REM with trim and fill & $35 \dagger$ & & 0.075 & 0.019 & 2.7 & $<0.0001$ & 34 & 150 & $<0.0001$ & 75 \\
\hline \multirow[t]{3}{*}{2} & \multirow{3}{*}{$\begin{array}{l}\text { Cognitive } \\
\text { domain }\end{array}$} & Original REM & 13 & 29269 & 0.14 & 0.016 & 8.5 & $<0.0001$ & 12 & 12 & 0.451 & 27 \\
\hline & & $\begin{array}{l}\text { REM with SE as } \\
\text { moderator }\end{array}$ & & & 0.132 & 0.030 & 4.3 & $<0.0001$ & 11 & 12 & 0.3836 & 29 \\
\hline & & REM with trim and fill & & & 0.140 & 0.017 & 8.2 & $<0.0001$ & 12 & 12 & 0.4510 & 27 \\
\hline \multirow[t]{3}{*}{3} & \multirow{3}{*}{$\begin{array}{l}\text { Affective } \\
\text { domain }\end{array}$} & Original REM & 13 & 38219 & 0.093 & 0.034 & 2.7 & 0.03 & 12 & 67 & $<0.0001$ & 77 \\
\hline & & $\begin{array}{l}\text { REM with SE as } \\
\text { moderator }\end{array}$ & & & 0.043 & 0.041 & 1.1 & 0.2935 & 11 & 57 & $<0.0001$ & 74 \\
\hline & & REM with trim and fill & $14 \dagger$ & & 0.088 & 0.028 & 3.1 & 0.0018 & 13 & 68 & $<0.0001$ & 76 \\
\hline
\end{tabular}

*Not the sum across the two domains as some studies are included in both domains.

†Includes original and imputed studies.

$\mathrm{N}^{\mathrm{s}}$, number of included studies; $\mathrm{N}^{\mathrm{p}}$, number of total included participants; REM, random-effects model.

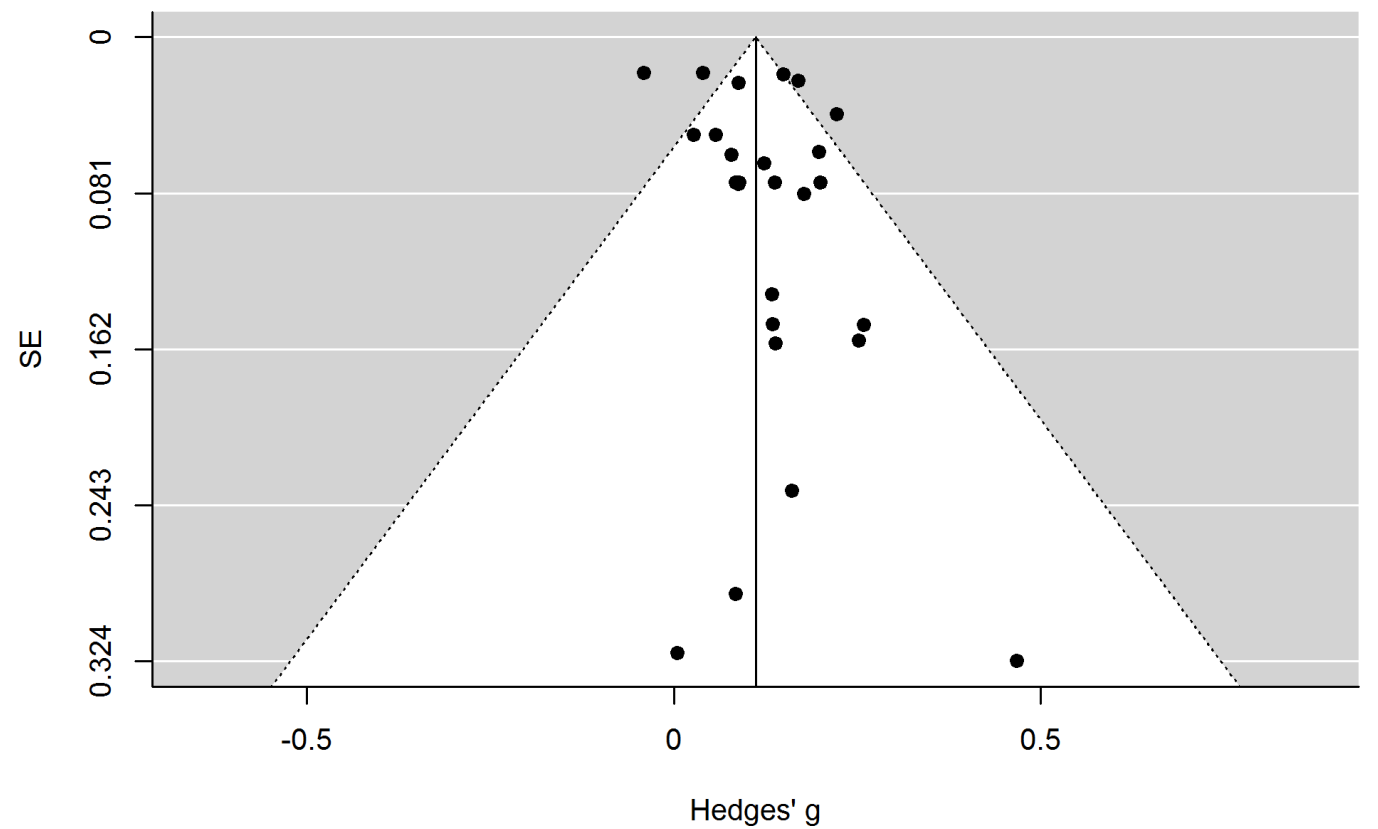

Figure 3 Funnel plot of original random-effects model of all included studies with their respective effect size and SEs.

analyses suggest that the adjusted overall summary effect size would be 0.075 (cf, table 3 ). It is still significant $(\mathrm{p}<0.0001)$, but smaller than the originally calculated summary effect size $(g=0.112)$. Additionally, even with the imputed effect sizes, there are still significant levels of heterogeneity present, which indicate that other factors than publication bias are contributing to the observed heterogeneity. Table 3 also shows that only the studies in the affective domain appear to be afflicted by publication bias, as the summary effect size for the cognitive domain remains unchanged with the trim and fill analysis. The results from regression-based adjustment for publication bias are consistent with the trim and fill analysis in that they show a similar overall effect size, a clear association in the cognitive domain and a noticeably weaker association in the affective domain.

\section{Moderator analyses}

Considering that performing a moderator analysis is generally not advisable with less than 10 studies, ${ }^{53}$ we performed a moderator analysis for the whole sample of studies, rather than separately for the affective domain. The following moderators were initially included in single-predictor models: publication year, child age at assessment, outcome domain and diet category. Instrument category was originally considered, but only questionnaires were used in the studies within the affective domain and this was therefore deemed unnecessary. 
Child age at assessment explained none of the heterogeneity and were excluded from further analysis. Separately, outcome domain, publication year and diet category accounted for some of the heterogeneity present, and when included together in a moderator analysis they explained approximately $30 \%$ of the heterogeneity $(\mathrm{p}=0.0471)$. However, there was still a significant degree of heterogeneity present $(\mathrm{p}<0.0001)$, indicating that other moderators not considered in the model were influencing the outcome effect sizes.

\section{Discussion}

The aim of this meta-analysis was to systematically review and summarise the currently existing literature about the association between maternal diet quality and different child neurodevelopmental outcomes. When dietary exposures believed to be appropriate proxies for maternal diet quality were included, a total of 18 studies comprising 63861 participants were found relevant for inclusion in this meta-analysis.

The meta-analysis showed that a better maternal diet quality had a small, statistically significant association with child neurodevelopment. The summary effect size for the cognitive domain was larger than the overall summary effect size, with no significant presence of heterogeneity. This positive association with cognitive outcomes is in line with findings from a recent narrative review investigating the association between maternal fish intake and child cognitive outcomes. ${ }^{57}$ The important contribution of our quantitative meta-analysis is the calculation of average effect sizes, which shows, also after correcting for publication bias, a small but robust association. The summary effect size for the affective domain was smaller than the overall summary effect size, with a large and significant degree of heterogeneity present. Considering that an overall summary effect size is most appropriate to use for studies with little heterogeneity, ${ }^{22}$ the summary effect size should be interpreted with caution. If we look at the effect sizes for all four outcome dimensions (cf, figure 2), we find that maternal diet quality is associated with all neurodevelopmental dimensions except for the internalising dimension, with the strongest associations seen for socioemotional and general cognitive functioning. However, these effect sizes are still considered small according to Cohens' interpretative guidelines. ${ }^{58}$

In the moderator analysis, outcome domain, publication year and diet category (type of dietary classificationdietary pattern or its proxies (fish intake, fruit intake, saturated fat intake or $\Omega-6 / \Omega-3$ fatty acid ratio) ) contributed significantly to the heterogeneity present in the total sample of studies, explaining $30 \%$ of the heterogeneity. However, a large degree of heterogeneity remained. As only the fully adjusted effect sizes from each study were included in the meta-analysis, unmeasured or unreported variables may have contributed to the remaining heterogeneity. Furthermore, these results might indicate that maternal diet might be of more importance for certain neurodevelopmental outcomes. However, we emphasise that this moderator analysis is only exploratory and the results should be seen as preliminary, given the small number of eligible studies included in the meta-analysis and the possible number of potential moderators.

The majority of the studies included in this meta-analysis using proxies of a maternal dietary pattern during pregnancy had fish or seafood intake as their exposure measure. Although fish intake most likely is a good marker for diet quality, there are limitations involved. One major limitation is that the studies investigating fish intake varied greatly with regard to intake group definitions,

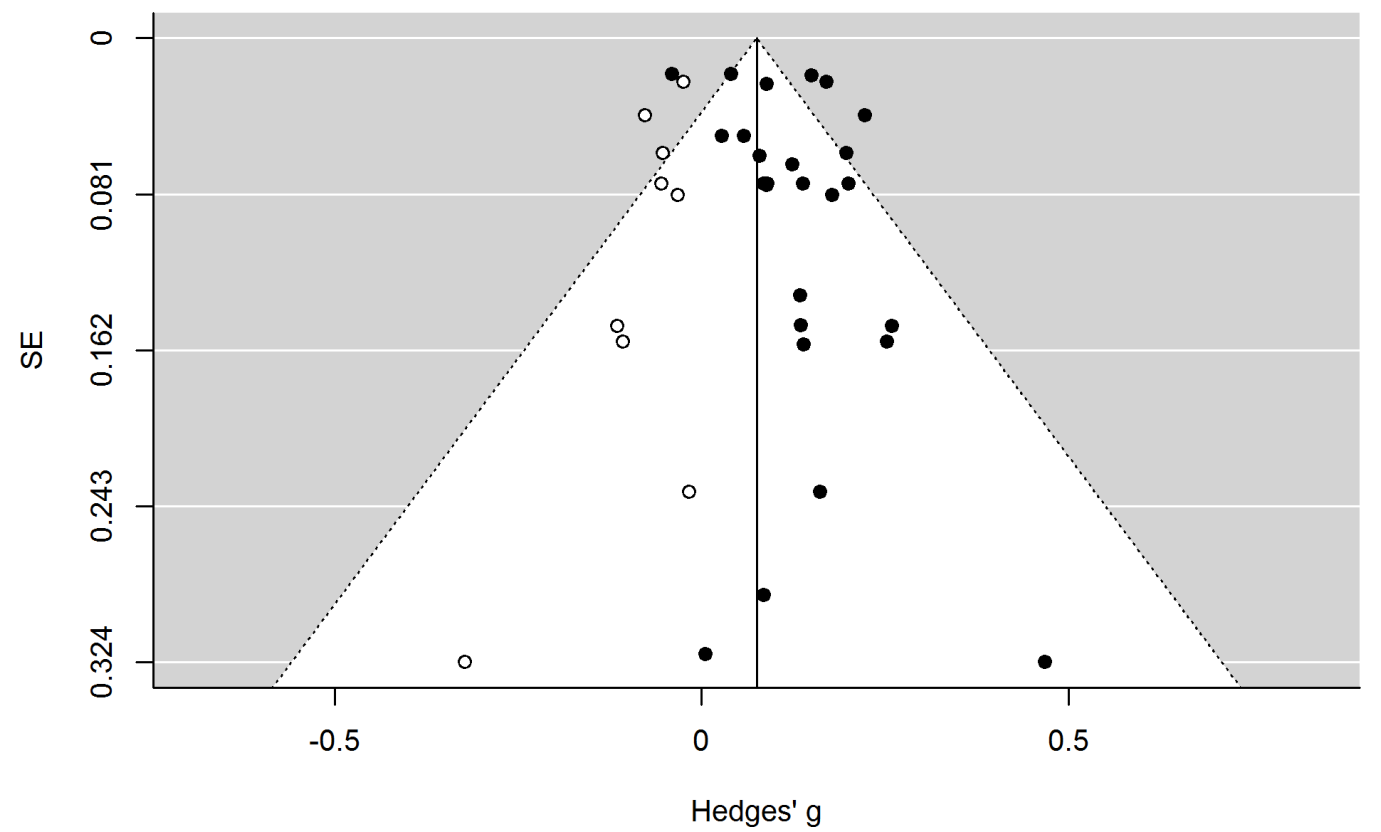

Figure 4 Funnel plot of random-effects model with trim and fill analysis, showing original studies (closed circle) and imputed studies (open circle). 
with division into two, three or four groups, where most groups were compared with a reference group (generally those who never or rarely consumed fish), or included as a continuous variable in a linear regression model. Some studies also compared extreme groups (lowest vs highest quintile), which were the studies reporting the largest effect sizes. Due to this varying dietary exposure definition, it is likely that the amount of heterogeneity the diet category accounts for is underestimated in the moderator analysis. Ideally, we could have used a more elaborate classification of categories, to reflect the actual diversity of the exposure measures, but this was not appropriate considering the small number of studies included in this meta-analysis. ${ }^{59}$

As seen from the funnel plot in figure 3 , there is a clear negative correlation between effect sizes and SE, indicating that the larger the sample size, the smaller the association between maternal diet quality and the outcome measure. This is not surprising, considering that the effect size of a study with a small sample needs to be large to reach significance in comparison to studies with a large sample size where only very small effect sizes are required to reach statistical significance. However, even if the observed pattern has a statistical explanation, a clear visual indication of publication bias remains. Accordingly, analyses that corrected for publication bias through a trim and fill procedure and meta-regression resulted in overall effect size estimates that were around 30\% lower compared with the effect size estimates from the original REM.

\section{Maternal diet—direct effect or marker for child diet?}

An important issue that cannot be resolved by this meta-analysis is whether the observed association is based on direct effects of maternal diet quality or whether it is a marker for the child's diet, which is a competing exposure that also influences child development. Not surprisingly, maternal diet quality as well as maternal postnatal diet and child diet during infancy and early toddlerhood have been found to be highly correlated. ${ }^{60-62}$ Therefore, it remains possible that the observed associations between maternal diet quality and child development are due to the child's diet after pregnancy. Ultimately, the interpretation of the reported effect sizes depends on the assumed causal model. If it is assumed that child diet is a mediator between maternal diet quality and child development, then one has to control for child diet if interested in the direct effect of maternal diet quality, and one must not control for child diet if interested in the total effect of maternal diet quality. ${ }^{6364}$ However, we suggest that maternal diet quality and child diet have a common cause-for example, parental education-and an unbiased estimate of the direct effects of maternal diet quality on child development requires controlling for child diet. One mitigating fact is that child diet varies with sociodemographic variables ${ }^{62}$ so that controlling for maternal postnatal diet and sociodemographic factors is likely to, at least in part, control for child diet. Still, child diet should ideally be assessed as a distinct factor. Indeed, the only study ${ }^{35}$ among the three studies that reported controlling for the child's diet, ${ }^{35} 3639$ which also provided unadjusted and adjusted effect sizes, found that the association between maternal diet quality and both externalising and internalising problems in the child was mediated by child diet, reducing the effect of maternal diet quality in three out of four analyses.

An important aspect of child diet during the earliest stages of life is breastfeeding. Previous studies exploring the association between breastfeeding and different cognitive development measures have found associations between longer breastfeeding duration and better general cognitive development, ${ }^{65-67}$ higher $\mathrm{IQ}^{68}$ better educational attainment ${ }^{69}$ and language development, ${ }^{70}$ as well as a lower risk of having ADHD. ${ }^{71}$ Nine of the studies included in this meta-analysis adjusted for breastfeeding duration, ${ }^{31} 3334374041434647$ but none provided information on both unadjusted and adjusted effect sizes related to breastfeeding specifically. However, some indicated that breastfeeding did not display a significant confounding effect.

In studies that stratified their sample by breastfeeding practices, ${ }^{36}{ }^{43}$ a significant association with maternal diet quality was only seen when the child had been breastfed for less than 6 months. This suggests that a better maternal diet quality might serve as a protective or beneficial factor to a larger degree for children who are not breastfed or breastfed less than the recommended period.

Maternal obesity is another factor related to both breastfeeding and the outcomes. Studies consistently show reduced breastfeeding rates in obese mothers ${ }^{72} 73$ and obesity is also linked to impaired cognition and increased behavioural problems in children. ${ }^{7-76}$ This highlights the importance of also accounting for maternal body mass index in the analysis, but only four studies did this in their analyses. ${ }^{37} 384041$

The effect of maternal diet quality on child development is an exemplary research topic where causal knowledge has to be extracted from observational studies because experimental studies are either unethical or impractical. ${ }^{77}$ However, if causal information is to be gleaned from observational data, care must be taken to control for biases due to, for example, self-selection into studies or selective dropout, for example by using inverse probability weights so that the effective sample better resembles the target population. Importantly, controlling by adding covariates is typically not sufficient to control, for example, selection bias. ${ }^{78}$ The appraisal of the summarised studies with the NOS suggests that while all summarised studies controlled, to varying degrees, for potential confounders by adding covariates to their analysis, systematic control for selection bias is not yet part of routine analysis.

\section{Limitations}

Only the fully adjusted effect sizes from each study were selected for inclusion into the meta-analysis; however, the 
confounders considered by each study varied greatly. This adds to the uncertainty of the results.

Only four of the studies included in this meta-analysis used maternal dietary patterns as their exposure measure for diet quality. Even though investigation of dietary patterns has received increasing interest over the past decade, there is still a lack of research in this area, particularly in relation to child cognitive outcomes. Additionally, there should be more focus on dietary patterns as opposed to global indices of healthy diets, as these indices inherently assume substitutability of different aspects of healthy diets, which might not be valid assumptions.

In the majority of the studies included with fish or seafood intake as the exposure measure, fish intake was not a part of the main exposure or primary investigation-it was often included as a covariate, with the main study focus being investigation of mercury exposure. This, together with the varying definition of fish intake between the studies, probably contributes substantially to the observed heterogeneity and illustrates the limitations involved in conducting a meta-analysis on studies with very heterogeneous exposure measures.

None of the studies reporting more than one effect size included information on the corresponding correlation between effect sizes. It is likely to assume that at least some of the effect sizes within each study were interdependent as they are measuring different aspects of the same overall cognitive or affective domain. It is widely recommended to aggregate dependent effect sizes to avoid biased estimates while at the same time account for possible dependencies within the sample of studies. ${ }^{22}$ This meta-analysis used non-independent effect sizes due to both multiple effect sizes reported from the same study as well as several studies using the same cohort as a basis for their study sample. However, we took care in accounting for these dependencies by calculating adjusted weights and robust SEs and performing an overall meta-analysis as well as individual meta-analyses for both domains. Moreover, three different REMs were fit (cf, table 3) to test for plausible moderators. Hence, despite the challenges posed by dependent effect sizes our analyses likely provides unbiased summary effect sizes for the association between maternal diet quality and child development.

Lastly, there are many challenges relating to the FFQ as a measurement tool, which is well known within the nutritional research field. ${ }^{79} 80$ This is mainly due to different types of bias that can arise from using self-report measures of dietary intake, which creates further difficulties in relation to analysis and interpretation of diet-health associations.

Taken together, these limitations suggest that while the effect sizes reported here provide some information about the association between maternal diet quality and child cognitive and affective outcomes, more research is needed to obtain reliable estimates of such associations.

\section{CONCLUSION}

Comparing studies looking at an overall maternal diet quality rather than specific nutrients brings with it many challenges, mainly due to heterogeneous methods for measuring intake, failure to account for child diet during early childhood as well as the vast number of confounders needed to be considered, both genetic and environmental.

Additionally, the number of studies available for inclusion in this meta-analysis is limited and they are heterogeneous, both with regard to exposure and outcome measures, indicating that results should be interpreted with caution. However, the results point in the direction that a better maternal diet quality is weakly, but robustly associated with a more favourable cognitive development and fewer affective problems in the child.

Lastly, it is important to emphasise that the studies included in this meta-analysis are all observational and do often take only limited steps towards causal identification. Therefore, causal interpretations of the results have to be avoided.

\section{Suggestions for future research}

The results of this meta-analysis highlight the need for more research on the effects of maternal diet quality on child cognitive and affective outcomes. The heterogeneity present in this sample of studies, particularly with regard to the definition of the exposure measures, makes comparison of results across studies particularly challenging. To better enable for between-study comparisons in the future, careful consideration should be taken to develop standardised instruments for the measurement of diet quality, which can be applicable, with minor modifications, across different populations. Additionally, studies should aim for the use of validated and recognised instruments for the measurement of cognitive and behavioural outcomes, rather than self-developed or obsolete instruments. With regard to the outcome measures, available reliability data for the instruments used by the included studies do not provide any clear distinction in test-retest reliability between questionnaires and clinical tests, ${ }^{81-95}$ but a comparison of effect sizes for outcomes assessed through questionnaires and clinical neuropsychological tests, within the same study, will help to settle this important issue.

Furthermore, it is crucial that future studies investigating the effect of maternal diet quality on child neurodevelopmental outcomes also consider the child's diet, as failure to recognise child diet as an important contributing factor limits the interpretability of such studies. More generally, more attention to and controlling of confounders, potential competing exposures and potential bias due to self-selection into studies or selective dropout will be important to better justify a causal interpretation of observational studies.

Finally, greater emphasis should be put on research transparency by means of describing the methodology used more exhaustively and by reporting complete results for both significant and non-significant results. 
Contributors TCB, GB and HA designed the study. TCB and ALB prepared the data in conjunction with GB. TCB and GB conducted the statistical analysis. TCB drafted the manuscript and had the primary responsibility for the final content. All authors critically reviewed, read and approved the final version of the manuscript. TCB is the guarantor.

Funding The present study was supported by a grant from NevSom; National Centre for Neurodevelopmental Disorders and Hypersomnia—ADHD, Autism, Tourette's syndrome and Hypersomnia (grant no. 51379 - 001/15-473).

Competing interests None declared.

Provenance and peer review Not commissioned; externally peer reviewed.

Data sharing statement Table with raw and calculated effect sizes, including corresponding statistics, from included studies and R script of all analysis performed for this meta-analysis is available upon request from the corresponding author Tiril Cecilie Borge; tibo@fhi.no.

Open Access This is an Open Access article distributed in accordance with the Creative Commons Attribution Non Commercial (CC BY-NC 4.0) license, which permits others to distribute, remix, adapt, build upon this work non-commercially, and license their derivative works on different terms, provided the original work is properly cited and the use is non-commercial. See: http://creativecommons.org/ licenses/by-nc/4.0/

(c) Article author(s) (or their employer(s) unless otherwise stated in the text of the article) 2017. All rights reserved. No commercial use is permitted unless otherwise expressly granted.

\section{REFERENCES}

1. Barker DJP. Mothers, babies and health in later life. 2nd ed. Edinburgh: Churchill Livingstone, 1998

2. Harding JE. The nutritional basis of the fetal origins of adult disease. Int J Epidemiol 2001;30:15-23.

3. Heindel JJ, Vandenberg LN. Developmental origins of health and disease: a paradigm for understanding disease cause and prevention. Curr Opin Pediatr 2015;27:248-53.

4. Thapar A, Cooper M, Jefferies R, et al. What causes attention deficit hyperactivity disorder? Arch Dis Child 2012;97:260-5.

5. Roseboom TJ, Painter RC, van Abeelen AF, et al. Hungry in the womb: what are the consequences? lessons from the dutch famine. Maturitas 2011;70:141-5.

6. Prado EL, Dewey KG. Nutrition and brain development in early life. Nutr Rev 2014;72:267-84.

7. Zeisel SH. Is maternal diet supplementation beneficial? optimal development of infant depends on mother's diet. Am J Clin Nutr 2009;89:685S-7.

8. Englund-Ögge L, Brantsæter AL, Sengpiel V, et al. Maternal dietary patterns and preterm delivery: results from large prospective cohort study. BMJ 2014;348:g1446-64.

9. $\mathrm{Hu} \mathrm{FB}, \mathrm{Fb} \mathrm{H}$. Dietary pattern analysis: a new direction in nutritional epidemiology. Curr Opin Lipidol 2002;13:3-9.

10. Moher D, Liberati A, Tetzlaff J, et al. Preferred reporting items for systematic reviews and meta-analyses: the PRISMA statement. Int $J$ Surg 2010;8:336-41.

11. Norwegian National Nutrition Council. Diet recommendations to promote public health and prevent chronic diseases - Methodology and evidence foundation. Oslo: Norwegian Health Directorate, 2011.

12. Simopoulos AP. The importance of the omega-6/omega-3 fatty acid ratio in cardiovascular disease and other chronic diseases. Exp Biol Med 2008;233:674-88.

13. Hooper L, Martin N, Abdelhamid A, et al. Reduction in saturated fat intake for cardiovascular disease. Cochrane Database Syst Rev 2015. Cd011737 doi (accessed 13 Jun 2015).

14. Anderson JW, Baird P, Davis RH, et al. Health benefits of dietary fiber. Nutr Rev 2009;67:188-205.

15. Balder HF, Virtanen M, Brants HA, et al. Common and countryspecific dietary patterns in four european cohort studies. J Nutr 2003;133:4246-51.

16. Knudsen VK, Orozova-Bekkevold IM, Mikkelsen TB, et al. Major dietary patterns in pregnancy and fetal growth. Eur J Clin Nutr 2008;62:463-70.

17. Willett WC, Sacks F, Trichopoulou A, et al. Mediterranean diet pyramid: a cultural model for healthy eating. Am J Clin Nutr 1995;61:1402S-6.

18. Guenther PM, Casavale $\mathrm{KO}$, Reedy J, et al. Update of the Healthy Eating Index: hei-2010. J Acad Nutr Diet 2013;113:569-80.
19. Wells G, Shea B, O'Connell D, et al; The Newcastle-Ottawa scale (NOS) for assessing the quailty of nonrandomised studies in metaanalyses, 2009. http://www.ohri.ca/programs/clinical_epidemiology/ oxford.asp.

20. The Cochrane Collaboration. 13.5.2.3 Tools for assessing methodological quality or risk of bias in non-randomized studies. In: Higgins JPT, Green S, eds. Cochrane Handbook for Systematic Reviews of Interventions. version 5.1.0. [updated March 2011] ed, 2011.

21. Stang A. Critical evaluation of the Newcastle-Ottawa scale for the assessment of the quality of nonrandomized studies in metaanalyses. Eur J Epidemiol 2010;25:603-5.

22. Del Re AC. A Practical Tutorial on conducting Meta-Analysis in R. The Quantitative Methods for Psychology 2015;11:37-50.

23. Viechtbauer W. Meta-Analysis Package for R, 2016. https://cran.rproject.org/web/packages/metafor/index.html.

24. Viechtbauer W. Conducting Meta-Analyses in $R$ with the metafor Package. J Stat Softw 2010;36:1-48.

25. Borenstein M, Hedges LV, Higgins JPT, et al; Introduction to MetaAnalysis. Chicester, United Kingdom: Wiley, 2009.

26. Siddiqi N. Publication Bias in epidemiological studies. Cent Eur J Public Health 2011;19:118-20.

27. Sterne JAC, Harbord RM. Funnel plots in meta-analysis. SJ 2004;4:127-41.

28. Egger M, Davey Smith G, Schneider M, et al. Bias in meta-analysis detected by a simple, graphical test. BMJ 1997;315:629-34.

29. Moreno SG, Sutton AJ, Ades AE, et al. Assessment of regressionbased methods to adjust for publication Bias through a comprehensive simulation study. BMC Med Res Methodol 2009;9:2.

30. Barker ED, Kirkham N, Ng J, et al. Prenatal maternal depression symptoms and nutrition, and child cognitive function. $\mathrm{Br} J$ Psychiatry 2013;203:417-21.

31. Daniels JL, Longnecker MP, Rowland AS, et al. Fish intake during pregnancy and early cognitive development of offspring. Epidemiology 2004;15:394-402.

32. Davidson PW, Strain JJ, Myers GJ, et al. Neurodevelopmental effects of maternal nutritional status and exposure to methylmercury from eating fish during pregnancy. Neurotoxicology 2008;29:767-75.

33. Gale CR, Robinson SM, Godfrey KM, et al. Oily fish intake during pregnancy--association with lower hyperactivity but not with higher full-scale IQ in offspring. J Child Psychol Psychiatry 2008;49:1061-8.

34. Hibbeln JR, Davis JM, Steer C, et al. Maternal seafood consumption in pregnancy and neurodevelopmental outcomes in childhood (ALSPAC study): an observational cohort study. The Lancet 2007;369:578-85.

35. Jacka FN, Ystrom E, Brantsaeter AL, et al. Maternal and early postnatal nutrition and mental health of offspring by age 5 years: a prospective cohort study. J Am Acad Child Adolesc Psychiatry 2013;52:1038-47.

36. Mendez MA, Torrent M, Julvez J, et al. Maternal fish and other seafood intakes during pregnancy and child neurodevelopment at age 4 years. Public Health Nutr 2009;12:1702-10.

37. Oken E, Radesky JS, Wright RO, et al. Maternal fish intake during pregnancy, blood mercury levels, and child cognition at age 3 years in a US cohort. Am J Epidemiol 2008;167:1171-81.

38. Oken E, Østerdal ML, Gillman MW, et al. Associations of maternal fish intake during pregnancy and breastfeeding duration with attainment of developmental milestones in early childhood: a study from the danish National Birth Cohort. Am J Clin Nutr 2008;88:789-96.

39. Pina-Camacho L, Jensen SK, Gaysina D, et al. Maternal depression symptoms, unhealthy diet and child emotional-behavioural dysregulation. Psychol Med 2015;45:1851-60.

40. Steenweg-de Graaff J, Tiemeier H, Steegers-Theunissen RP, et al. Maternal dietary patterns during pregnancy and child internalising and externalising problems. the generation R study. Clin Nutr 2014;33:115-21.

41. Valent F, Mariuz M, Bin M, et al. Associations of prenatal mercury exposure from maternal fish consumption and polyunsaturated fatty acids with child neurodevelopment: a prospective cohort study in Italy. J Epidemiol 2013;23:360-70

42. Sagiv SK, Thurston SW, Bellinger DC, et al. Prenatal exposure to mercury and fish consumption during pregnancy and attentiondeficit/hyperactivity disorder-related behavior in children. Arch Pediatr Adolesc Med 2012;166:1123-31.

43. Bernard JY, De Agostini M, Forhan A, et al. The dietary n6:n3 fatty acid ratio during pregnancy is inversely associated with child neurodevelopment in the EDEN mother-child cohort. J Nutr 2013;143:1481-8.

44. Bolduc FV, Lau A, Rosenfelt CS, et al. Cognitive enhancement in Infants Associated with increased Maternal Fruit Intake during 
Pregnancy: results from a Birth Cohort Study with Validation in an Animal Model. EBioMedicine 2016;8:331-40.

45. Gustafsson HC, Kuzava SE, Werner EA, et al. Maternal dietary fat intake during pregnancy is associated with infant temperament. Dev Psychobiol 2016;58:528-35.

46. Julvez J, Méndez M, Fernandez-Barres S, et al. Maternal consumption of Seafood in Pregnancy and Child Neuropsychological Development: a Longitudinal Study based on a Population with High Consumption levels. Am J Epidemiol 2016;183:169-82.

47. Oken E, Rifas-Shiman SL, Amarasiriwardena C, et al. Maternal prenatal fish consumption and cognition in mid childhood: mercury, fatty acids, and selenium. Neurotoxicol Teratol 2016;57:71-8.

48. Del Re A. Compute effect sizes (Package "compute.es", 2014. https://cran.r-project.org/web/packages/compute.es/.

49. Chinn S. A simple method for converting an odds ratio to effect size for use in meta-analysis. Stat Med 2000;19:3127-31.

50. Lakens D. Calculating and reporting effect sizes to facilitate cumulative science: a practical primer for t-tests and ANOVAs. Front Psychol 2013;4:863.

51. Altman DG, Bland JM. How to obtain the confidence interval from a $P$ value. Br Med J 2011;343.

52. Altman DG, Bland JM. How to obtain the $P$ value from a confidence interval. Br Med J 2011;343.

53. The Cochrane Collaboration. Cochrane Handbook for Systematic Reviews of Interventions, Higgins J, Green S. Editors 2011 www. cochrane-handbook.org.

54. Sjöwall D, Backman A, Thorell LB. Neuropsychological heterogeneity in Preschool ADHD: investigating the interplay between Cognitive, Affective and motivation-based forms of regulation. J Abnorm Child Psychol 2015;43:669-80.

55. Gutiérrez-Cobo MJ, Cabello R, Fernández-Berrocal P. The relationship between Emotional Intelligence and Cool and Hot Cognitive Processes: a systematic review. Front Behav Neurosci 2016;10:101.

56. Hedges LV, Tipton E, Johnson MC. Robust variance estimation in meta-regression with dependent effect size estimates. Res Synth Methods 2010;1:39-65.

57. Starling P, Charlton K, McMahon AT, et al. Fish intake during pregnancy and foetal neurodevelopment--a systematic review of the evidence. Nutrients 2015;7:2001-14.

58. Cohen J. Statistical power analysis for the behavioral sciences. 2nd ed. Hillsdale: N. J: Laurence Erlbaum, 1988.

59. Hedges LV, Pigott TD. The power of statistical tests for moderators in meta-analysis. Psychol Methods 2004;9:426-45.

60. Ashman AM, Collins CE, Hure AJ, et al. Maternal diet during early childhood, but not pregnancy, predicts diet quality and fruit and vegetable acceptance in offspring. Matern Child Nutr 2016;12.

61. Fisk CM, Crozier SR, Inskip HM, et al. Influences on the quality of young children's diets: the importance of maternal food choices. $\mathrm{Br} J$ Nutr 2011:105:287-96.

62. Emmett PM, Jones LR, Northstone K. Dietary patterns in the Avon Longitudinal Study of Parents and Children. Nutr Rev 2015;73 Suppl 3:207-30.

63. Hernán MA, Robins JM. Causal Inference. Boca Raton: Chapman \& Hall/CRC, forthcoming. 2016. https://www.hsph.harvard.edu/miguelhernan/causal-inference-book/.

64. Greenland S, Pearl J, Robins JM. Causal diagrams for epidemiologic research. Epidemiology 1999;10:37-48.

65. Julvez J, Guxens M, Carsin AE, et al. A cohort study on full breastfeeding and child neuropsychological development: the role of maternal social, psychological, and nutritional factors. Dev Med Child Neurol 2014;56:148-56.

66. Quigley MA, Hockley C, Carson C, et al. Breastfeeding is associated with improved child cognitive development: a population-based cohort study. J Pediatr 2012;160:25-32.

67. Kramer MS, Aboud F, Mironova E, et al. Breastfeeding and child cognitive development: new evidence from a large randomized trial. Arch Gen Psychiatry 2008;65:578-84.

68. Brion MJ, Lawlor DA, Matijasevich A, et al. What are the causal effects of breastfeeding on IQ, obesity and blood pressure? evidence from comparing high-income with middle-income cohorts. Int $J$ Epidemiol 2011;40:670-80.

69. Groen-Blokhuis MM, Franić S, van Beijsterveldt CE, et al. A prospective study of the effects of breastfeeding and FADS2 polymorphisms on cognition and hyperactivity/attention problems. Am J Med Genet B Neuropsychiatr Genet 2013;162B:457-65.

70. Smith JM. Breastfeeding and language outcomes: a review of the literature. J Commun Disord 2015;57:29-40.
71. Stadler DD, Musser ED, Holton KF, et al. Recalled Initiation and Duration of Maternal Breastfeeding Among Children with and Without ADHD in a Well Characterized Case-Control Sample. J Abnorm Child Psychol 2016;44:347-55.

72. Newby RM, Davies PS. Antenatal breastfeeding intention, confidence and comfort in obese and non-obese primiparous australian women: associations with breastfeeding duration. Eur J Clin Nutr 2016;70:935-40.

73. Bever Babendure J, Reifsnider E, Mendias E, et al. Reduced breastfeeding rates among obese mothers: a review of contributing factors, clinical considerations and future directions. Int Breastfeed J 2015;10:21.

74. Pugh SJ, Hutcheon JA, Richardson GA, et al. Gestational weight gain, prepregnancy body mass index and offspring attention-deficit hyperactivity disorder symptoms and behaviour at age 10. BJOG 2016;123:2094-103.

75. Pugh SJ, Richardson GA, Hutcheon JA, et al. Maternal obesity and excessive gestational Weight Gain are associated with Components of Child Cognition. J Nutr 2015;145:2562-9.

76. Veena SR, Gale CR, Krishnaveni GV, et al. Association between maternal nutritional status in pregnancy and offspring cognitive function during childhood and adolescence; a systematic review. BMC Pregnancy Childbirth 2016;16:220.

77. Rothman KJ. Epidemiology: an introduction. Oxford University Press: Oxford, 2002.

78. Hernán MA, Hernández-Díaz S, Robins JM. A structural approach to selection Bias. Epidemiology 2004;15:615-25.

79. Freedman LS, Schatzkin A, Midthune D, et al. Dealing with dietary measurement error in nutritional cohort studies. J Natl Cancer Inst 2011;103:1086-92.

80. Kipnis V, Midthune D, Freedman L, et al. Bias in dietary-report instruments and its implications for nutritional epidemiology. Public Health Nutr 2002;5:915-23.

81. Adams W, Sheslow D. Wide Range Assessment of Visual Motor abilities (WRAVMA. Novato, CA: Academic Therapy Publications, 1995.

82. Baron RM, Kenny DA. The moderator-mediator variable distinction in social psychological research: conceptual, strategic, and statistical considerations. J Pers Soc Psychol 1986;51:1173-82.

83. Bayley N. Bayley Scales of Infant and Toddler Development, Technical Manual. 3rd ed. San Antonio TX: Harcourt Assessment, 2006.

84. Bilenberg N. The Child Behavior Checklist (CBCL) and related material: standardization and validation in danish population based and clinically based samples. Acta Psychiatr Scand Suppl 1999;398:2-52.

85. Canning EH, Kelleher K. Performance of screening tools for mental health problems in chronically ill children. Arch Pediatr Adolesc Med 1994;148:272-8.

86. Fenson L, Dale PS, Reznick JS, et al; The MacArthur Communicative Development inventories: user's guide and technical manual. San Diego: Singular Publishing Group, 1993.

87. Frankenburg WK, Dodds J, Archer P, et al. The Denver II: a Major revision and restandardization of the Denver developmental screening test. Pediatrics 1992;89:91-7.

88. Goodman R. Psychometric properties of the strengths and difficulties questionnaire. J Am Acad Child Adolesc Psychiatry 2001;40:1337-45.

89. McCarthy D. Manual for the McCarthy scales of children's abilities. New York: The Psychological Corporation, 1972.

90. McDevitt SC, Carey WB. The measurement of temperament in 3--7 year old children. J Child Psychol Psychiatry 1978;19:245-53.

91. Nøvik TS. Validity of the Child Behaviour Checklist in a norwegian sample. Eur Child Adolesc Psychiatry 1999;8:247-54.

92. Squires J, Twombly E, Bricker D, et al. Ages and Stages Questionnaire - Technical report. Baltimore, MD: brookes Publishing Co. Inc 2009.

93. Stone LL, Otten R, Engels RC, et al. Psychometric properties of the parent and teacher versions of the strengths and difficulties questionnaire for 4- to 12-year-olds: a review. Clin Child Fam Psychol Rev 2010;13:254-74.

94. Williams KT, Wang J. Technical references to the Peabody Picture Vocabulary Test- Third Edition (PPVT-III. Circle Pines, MN: American Guidance Service, 1997.

95. Williams PE, Weiss LG, Rolfhus EL. WISC-IV Technical Report \#2 Psychometric Properties: The Psychological Corporation, 2003. 